\title{
Characterization of the bacterial flora of tilapia (Oreochoromis niloticus) harvested from four lakes in the north of Cameroon
}

\author{
N. Nganou Donkeng ${ }^{1,2}$, J. Maiwore ${ }^{1}$, L. Tatsadjieu Ngoune $^{2^{\star}}$, D. Montet ${ }^{3}$ and C. M. F. Mbofung ${ }^{1}$ \\ ${ }^{1}$ Department of Food Science and Nutrition, Food Microbiology laboratory, National School of Agro-Industrial Sciences, \\ University of Ngaoundere, B.P. 455 ENSAI, Cameroon. \\ ${ }^{2}$ Department of Food Technology and Quality Control, University Institute of Technology, University of Ngaoundere, B.P. \\ 455 IUT, Cameroon. \\ ${ }^{3}$ UMR 95 Qualisud, CIRAD, TA B-95/16, 73, rue Jean-François Breton, 34398 Montpellier cedex 5, France.
}

Accepted 5 September, 2011

\begin{abstract}
The aim of this study was to investigate the presence of Aeromonas spp., Vibrio spp. and Plesiomonas shigelloides in Cameroonian tilapia.120 samples of tilapia were collected from June to December 2005 in four localities in the north of Cameroon and were delivered to the laboratory in cool boxes. For the sample preparation to isolate the bacteria, $50 \mathrm{~g}$ of sample (gills, intestine and skin of individually fish) were taken using a sterile scalpel. These $50 \mathrm{~g}$ were homogenized in $450 \mathrm{ml}$ of sterilised peptone solution. After $18 \mathrm{~h}$ of incubation, the homogenate sample was inoculated on thiosulphate citrate bile salt sucrose (TCBS) using an inoculation loop and incubated at $37^{\circ} \mathrm{C}$ for 18 to $24 \mathrm{~h}$. The isolated colonies were subjected to morphological, physiological and commercially available API kits tests. In addition, the antimicrobial pattern of the identified strains to ten different antibiotics was studied using the agar disk diffusion method. The results obtained from this study show the presence of bacterial species belonging to Aeromonas spp. $(n=39)$, Vibrio spp. $(n=41)$ and $P$. shigelloides $(n=14)$. The results of antimicrobial susceptibility show that the highest rates of resistance was found in ampicillin $(100 \%$ of isolates), nitrofurantoin (more than $68 \%$ of isolates), association of trimethoprim and sulfamethoxazole ( $51 \%$ of isolates) and sulfamide ( $46 \%$ of isolates). This work therefore highlights an important incidence of Aeromonas spp., Vibrio spp. and P. shigelloides with potential antimicrobial resistance, isolated from tilapia in four localities of Cameroon.
\end{abstract}

Key words: Aeromonas spp., Vibrio spp., Plesiomonas shigelloides, tilapia, antimicrobial resistance.

\section{INTRODUCTION}

With restrictions put in place on certain fishes in the western world, tilapia seems to be an alternative to traditional species of white fishes in European and American markets. Tilapia represents the second largest group of fish produced from aquaculture after Cyprinnidae (Ofimer, 2002). With a firm texture, white in colour, easy to cook, an added advantage of this species is that it is relatively available in good quantities and is

*Corresponding author. E-mail: tatsadjieu@yahoo.fr. Tél: $+(237) 9523727$. considered by some as the real "water-chicken". It constitutes a non negligible food source to most countries where it is cultivated. In addition, the skin of this fish can withstand preservation techniques such as freezing.

Despite these advantages, tilapia and fish in general can be contaminated with pathogenic microorganisms because of the texture of their flesh, their living habits and also from the microbe laden habitat they inhabit. Among these pathogenic microorganisms, Aeromonas spp., Vibrio spp. and $P$. shigelloides belong to the expanding group of water and food borne pathogens. They are widely distributed in an aquatic environment and have been implicated as opportunistic pathogens 
causing gastroenteritis in human beings. Their occurrence has been reported in some Asian and European countries. However, information on their occurrence in aquatic environments in Africa and their antimicrobial susceptibility is limited.

In many countries, the release of pathogenic bacteria in faeces dispersed into aquatic environments can contaminate fish and shellfish harvested from these waters. Once these bacteria are in the aquatic environment, plasmid exchange between the bacteria is readily facilitated and can result in a higher frequency of multiple antibiotic resistant strains. Local selective pressures could influence the antibiotic resistance. Chang and Bolton (1987) found that a greater percentage of Asian isolates of Aeromonas hydrophila were resistant to tetracycline and rifampicin than Australian isolates.

Antibiotic-resistant bacteria (Aoki, 1992; Austin and Austin, 1993) and antibiotics (Morita et al., 1994) are discharged to varying degrees in the environment as a result of the increasing and often indiscriminate use of antibiotics in medical, veterinary and agricultural practices. River waters are the main acceptable medium for these pollutants, since they receive the sewage of urban effluents. Most investigation on antibiotic resistance in the aquatic habitat has concerned bacteria of faecal origin, because they are used as pollution indicators and may be associated with infectious diseases. However, in many freshwater systems, faecal bacteria are of little numerical significance despite the fact that they are discharged into almost all inland water (Rasmussen et al., 1997). Thus, if the environmental pool of resistance is to be measured, bacteria other than those of faecal origin must be considered. Other studies were interested in whole bacterial populations (Enterobacteriaceae, gram-negative bacteria, heterotrophic bacteria or viable bacteria) and dealt with global antibiotic resistance (the frequency of cells able to grow on antibiotic-supplement media). Such studies cannot differentiate intrinsic resistance, that is, specific resistance (Kado et al., 1981), from acquired resistance due to either chromosomal mutations or incoming and thus transferable genes, mainly carried by plasmid or transposable elements (Schmidt et al., 2001).

Considering these facts, this study was carried out with an objective to provide information on the presence of Vibrionaceae in tilapias from four lakes in the north region of Cameroon, with a total annual production of 210 tons (FAO, 2004). The specie's prevalence, virulence factor and antimicrobial susceptibility of the bacterial strains isolated, were also studied.

\section{MATERIALS AND METHODS}

\section{Fish sampling}

The fish samples used in this study were tilapia and they were collected in four lakes situated respectively in three regions: Far north (Yagoua and Maga), north (Lagdo) and Lake Chad (Figure 1).
On each site, four fishes were collected and transferred in sterile storage bags. Fish harvest was carried out within the period June to December 2005. After the collection, samples were delivered to the laboratory in cool boxes.

\section{Isolation of bacteria}

In order to prepare isolation of bacteria from each fish, $50 \mathrm{~g}$ of a mixture (gills, intestines and skin) were taken using a sterile scalpel and mixed with $450 \mathrm{ml}$ sterile buffered peptone water, chopped with a stomacher and the mixture was homogenised. Serial dilution was done up to $10^{4}$. Portions $(100 \mu \mathrm{l})$ from each dilution were plated on a thiosulphate citrate bile salt sucrose (TCBS) agar (HiMedia, Bombay, India) and nutrient agar supplemented with $\mathrm{NaCl}$. The plates were incubated at $30^{\circ} \mathrm{C}$ for 24 to $48 \mathrm{~h}$. Stock cultures were stored after growth on a nutrient broth medium for $24 \mathrm{~h}$ at $30^{\circ} \mathrm{C}$, after which $1 \mathrm{ml}$ of culture (broth medium) of each pure strain was transferred into a sterile cryotube ( 3 per strain) on which was added $1 \mathrm{ml}$ of $40 \%$ sterile glycerol to obtain a final concentration of $20 \%$. The cryotubes were stored in a freezer at $-20^{\circ} \mathrm{C}$. The same analyses were carried out on water samples collected from the same sampling points.

\section{Bacterial selection}

Morphological observations and biochemical tests were used to identify the different strains. Morphologically, three parameters were studied: characteristics of the colonies, mobility, and Gram coloration. For biochemical tests, the catalase and oxydase reactions as well as identification based on the API kit were carried out.

\section{Antibiotic susceptibility}

Antibiotic susceptibility was determined by the agar diffusion method according to French National Guidelines (SFM, 2004). Bacterial suspension prepared in sterile $0.85 \%$ saline matching an optical density of $0.5 \mathrm{McF}$ arland standards corresponding to $10^{8}$ $\mathrm{cfu} / \mathrm{ml}$ and diluted 1:100 in saline were inoculated on the surface of a Muller-Hinton agar (Difco, le pont de claix, France). Each antibiotic test was run in duplicate on freshly prepared agar plates. After incubation for $24 \mathrm{~h}$ at $37^{\circ} \mathrm{C}$, microorganisms were classified as sensitive, intermediate or resistant according to the inhibition zone diameter (SFM, 2004). The tested antibiotics and their concentration used are presented in Table 1. Antibiotic discs were purchased from Bio-Rad laboratory (Marnes-la-coquette, France). Reference strain Escherichia coli ATCC 25922 (Institut Pasteur CIP 7624) was used as a control organism.

\section{RESULTS}

\section{Bacteria isolation and identification}

The results presented in this paper were obtained after analyses carried out on tilapias and water samples from the sampled localities.

The results obtained on nutrient agar (non-selective medium) made it possible to isolate and purify 197 strains for the four localities (Lake Chad, Lagdo, Maga and Yagoua) (Table 2). All the strains isolated from the tilapia fish and water were bacilli gram negative, and was identified using the API 20E kit. 


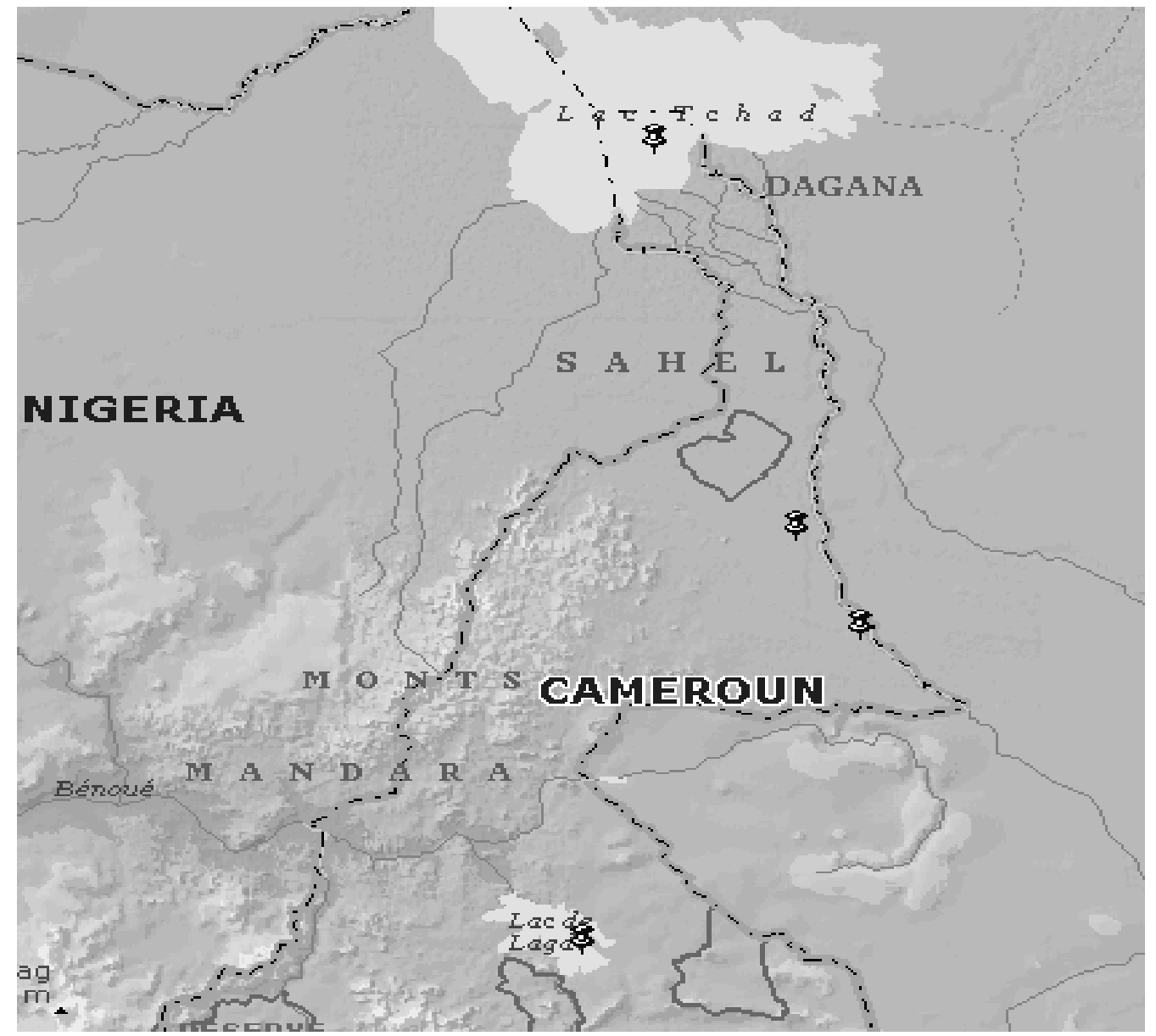

Figure 1. The northern part of Cameroon with four different sampling locations: Lake Chad, Lagdo, Maga and Yagoua.

From the tilapia fish of Lake Chad, (62) strains isolated and identified were species of Acinetobacter spp., Enterobacter cloacae, P. aeruginosa, Aeromonas sobria and Achromobacter spp. Analysis of lake water allowed the observation of all species found on the fish with several other species namely, Aeromonas hydrophila, Chryseomonas luteola, Bordetella spp., Proteus vulgaris and Edwarsiella tarda.

On tilapia fish of Maga, all the 74 strains isolated and identified were composed of species of: Pseudomonas fluorescens, Enterobacter sakazaki, Serratia marcescens, Pasteurella multicida, Pseudomonas putrefascians and Providencia stuartii. In the water of Maga in addition to species on the fish, several other species were found: Enterobacter amnigenus, Aeromonas hydrophila, Vibrio vulnifucus, Pasteurella spp., and Enterobacter cloacae. 43 strains were isolated on tilapia fish from Yagoua and species identified were: Enterobacter agglomerans, Klebsiella spp. Rhinoscleromatis, Pseudomonas pseudomalei, Weksiella virosa, Pasteurella sp. and Erwinia spp. In the Yagoua water, in addition to species on the fish, several other species were found such as Vibrio metschnikovii, Vibrio hollisea, Erwinia nigrifluens, $P$. fluorescens, Flavobacterium meningosepticum, P. pseudomalei, W. virosa, Pasteurella spp and Erwinia spp. On tilapia fish of Lagdo, 20 strains were isolated and it was observed after identification that they belong to Pasteurella spp. and Plesiomonas shigelloides species. Analysis of Lagdo water strains isolated and identified included in addition to the species found on the fish three other species; Erwinia spp, Klebsiella spp. and Enterobacter cloacae. Worthy of note is the absence of $E$. coli among all the isolated strains.

The result obtained on TCBS medium (selective for Vibrio) or on xylose lysine deoxycholate (XLD; selective for Aeromonas) made it possible to obtain strains of Aeromonas, Vibrio and P. shigelloides (Table 2); 14 strains of $P$. shigelloides from tilapia fishes of Lagdo, 15 strains of $V$. metschnikovii from tilapia fishes of Yagoua, 11 strains of $V$. alginolyticus, 13 strains of $V$. vulnificus and 12 strains of $A$. hydrophila from tilapia fishes of Maga, 13 strains of Aeromonas sobria and 14 strains of A. hydrophila from tilapia fishes of Lake Chad. 
Table 1. List of tested antibiotics, dics concentrations, critical concentrations and diameter defined by SFM for the different antibiotic (SFM, 2004).

\begin{tabular}{|c|c|c|c|c|c|}
\hline \multirow{2}{*}{ Antibiotic } & \multirow{2}{*}{ Disc concentration } & \multicolumn{2}{|c|}{ Critical concentrations (mg/L) } & \multicolumn{2}{|c|}{ Critical diameter $(\mathrm{mm})$} \\
\hline & & $\mathrm{s}$ & $\mathbf{R}$ & $\mathbf{S}$ & $\mathbf{R}$ \\
\hline Oxytetracycline & $30 \mathrm{UI}$ & $\leq 4$ & $>8$ & $\geq 19$ & $<7$ \\
\hline Oxolinic acid & $10 \mu \mathrm{g}$ & $\leq 2$ & $>4$ & $\geq 20$ & $<17$ \\
\hline Chloramphenicol & $30 \mu \mathrm{g}$ & $\leq 8$ & $>16$ & $\geq 23$ & $<19$ \\
\hline
\end{tabular}

\section{Streptomycin}

Streptococcus

Enterococcus

\section{Other bacteria}

Erythromycine

Trimethoprime/sulfamethoxazole

Nitrofuranes

Sulfamides

Flumequine

Ampicilline

Nalidixic acid
$500 \mu \mathrm{g}$

$10 \mathrm{UI}$

$15 \mathrm{UI}$

$1.25 / 23.75 \mu \mathrm{g}$

$300 \mu \mathrm{g}$

$200 \mu \mathrm{g}$

$30 \mu \mathrm{g}$

$10 \mu \mathrm{g}$

$30 \mu \mathrm{g}$

$$
\begin{array}{ll}
\leq 250 & >500 \\
\leq 8 & >16
\end{array}
$$$$
\begin{array}{ll}
\geq 14 & <12 \\
\geq 16 & <14
\end{array}
$$

\section{Antibiotic susceptibility of Vibrionaceae isolated from tilapia fishes}

The results of antimicrobial susceptibility (Table 4) show that the highest rates of resistance were found in ampicillin (100\% of isolates), nitrofurantoin (more than $68 \%$ of isolates), association of trimethoprim and sulfamethoxazole ( $51 \%$ of isolates) and sulfamide ( $46 \%$ of isolates).

Table 4 presents the relation between the isolated strains from the fishes and their resistances to antibiotics. All isolated strains studied were resistant to a combination of trimethoprime and sulfamethoxazole, but with a more accentuated resistance of the Vibrio spp. greater than $60 \%$. For the antibiotic nitrofurantoin, $A$. hydrophila showed a $100 \%$ resistance.

Strains of Aeromonas were especially resistant to sulfamid, with 88 and $62 \%$ for $A$. hydrophila and $A$. sobria, respectively. On the other hand, strains of $V$. vulnificus presented an elevated sensitivity $(77 \%)$ for this antibiotic. $V$. alginoliticus had an intermediary rate of $90 \%$. Of all studied strains, only $V$. alginoliticus presented a high percentage resistance to chloramphenicol $(82 \%)$, whereas the other strains had a sufficiently elevated sensitivity for this antibiotic (> 50\%). In a similar pattern, sensitivity rate increased for nalidixic and oxolinic acids, as well as for streptomycin. Only $V$. alginoliticus was resistant to nalidixic acid, $P$. shigelloides presented intermediary resistance to Nalidixic acid $(57 \%)$ and to streptomycin (64\%).

\section{DISCUSSION}

After fishes and water analyses, it was observed that gram negative bacilli isolated from the water were found in the tilapia fish, respectively, as a result of their contamination of this habitat. De Sousa and Silva-Souza (2001) showed a direct link between bacterial community of river water and microflora commencal of fish that live there. Bacteria present in water can be ingested by a fish and thus modify the dominant bacteria in its body (Sugita et al., 1996; Apun et al., 1999). In addition, water analyses have showed that each lake has its bacterial community. So this bacterial community was different from one lake to the other. Although, there is no certainty 
Table 2. Distribution of isolated bacterial strains from tilapia fish from the four localities in the north of Cameroon between June and December 2005.

\begin{tabular}{lccccc}
\hline Bacterial species & Yagoua & Lagdo & Maga & Lake Chad & Total \\
\hline Achromobacter & - & - & - & 6 & 6 \\
Acinetobacter spp. & - & - & - & 5 & 5 \\
Aeromonas hydrophila & - & - & 12 & 14 & 26 \\
Aeromonas sobria & - & - & - & 13 & 13 \\
Enterobacter agglomerans & 3 & - & - & - & 3 \\
Enterobacter sakazaki & - & - & 10 & - & 10 \\
Enterobacter cloacae & - & - & - & 12 & 12 \\
Erwinia spp. & 3 & - & - & - & 3 \\
Klebsiella pn spp. & 3 & - & - & - & 3 \\
Rhinoscleromatis & - & - & 7 & - & 7 \\
Pasteurella multicida & 11 & 6 & 7 & - & 24 \\
Pasteurella spp. & - & 14 & - & - & 14 \\
Plesiomonas shigelloides & - & - & 3 & - & 3 \\
Providencia stuartii & - & - & - & 12 & 12 \\
Pseudomonas aeruginosa & - & - & 3 & - & 3 \\
Pseudomonas fluorescens & 3 & - & - & - & 3 \\
Pseudomonas pseudomalei & - & - & 3 & - & 3 \\
Pseudomonas putrefasciens & - & - & 3 & - & 3 \\
Serratia marcescens & - & - & 13 & - & 13 \\
Vibrio alginolyticus & 15 & - & - & - & 15 \\
Vibrio metschnikovii & - & - & 13 & - & 13 \\
Vibrio vulnifucus & 5 & - & - & - & 5 \\
Weksiella virosa & 43 & 20 & 74 & 62 & 197 \\
Total & & & & & \\
\hline & & & - & & 3 \\
\hline
\end{tabular}

with regard to the existence of aquatic bacteria, the most widespread opinion among various authors is that most bacteria found in the aquatic environment are from the soil, introduced by rainwater or by accident: direct consequence of human activities (Stead, 1992).

Pathogens belonging to the family of Vibrionacea, were isolated from fish in four localities of the study and their variation from one lake to another confirms the hypothesis that the environment has an effect on the bacterial ecology of food. Thompson et al. (2001) studied the genomic diversity of the vibrio species which proved to be omnipresent, while seemed to be distinctive for the particular host or geographical area. Ratanaporn (2005) showed that bacteria found in cat-fishes in Vietnam and tilapias from Thailand are mostly gram negative. The most frequently isolated genera in tilapias from Khon Kaen are Pseudomonas, Enterobacter and Acinobacter, whereas the genera Enterobacter, Klebsiella Pseudomonas and Staphylococcus are frequently found in Tilapia niloticus from Nakorn Ratchasima.

Resistance to several antibiotics is the cause of frequent diseases attack in fishes. In this study, bacteria isolated from the fish were resistant to almost all anti- biotics tested. Many studies suggest an interrelationship between increased levels of bacterial resistance of farm fishes and the use of antimicrobial agents (Spanggaard et al, 1993; Guardabassi et al, 2000). In addition, since antimicrobial agents are released into the surrounding water during treatment of bacterial fish diseases, there is a direct and negative impact on the aquaculture environment (Annapurna et al., 1977; Popoff et al., 1976). Austin and Adams, (1996) demonstrated that most Aeromonas isolates from fishes are resistant to amoxicillin, carbencilin and ticarcillin.

Aeromonas strains are considered naturally resistant to ampicillin, which is generally included in culture media for isolation of Aeromonas; but this observation was based only on studies using clinical isolates and it is possible that in natural environments the selective constraints may be different. Although, it has been showed that strains of A. hydrophila isolated from trout are more sensitive to antibiotics than those isolated from clinical specimens, the environmental incidence of resistance to beta-lactam antibiotics seems to be increasing and is of popular concern with respect to impenem. The aquaculture environment may thereby constitute a reservoir for 
Table 3. Characteristics of Vibrio, Aeromonas and Plesiomonas isolated from tilapia fish from four localities in north Cameroon between June to December 2005.

\begin{tabular}{|c|c|c|c|c|c|c|}
\hline Parameter & V. metschnikoviii & V. alginolyticus & V. vulnificus & A. hydrophila & A. sobria & P.shigelloides \\
\hline Growth at $3 \% \mathrm{Nacl}$ & + & + & + & + & + & + \\
\hline Growth at $6 \% \mathrm{Nacl}$ & + & + & + & + & + & + \\
\hline Growth at 8\% Nacl & nd & nd & nd & nd & nd & nd \\
\hline Growth at $10 \% \mathrm{Nacl}$ & nd & nd & nd & nd & nd & nd \\
\hline Growth at $42^{\circ} \mathrm{C}$ & + & + & + & nd & nd & nd \\
\hline Mobility & + & + & + & + & + & + \\
\hline Oxydase & + & + & + & + & + & + \\
\hline ONPG & - & - & + & + & + & + \\
\hline Arginine dihydrolase & + & - & - & + & + & + \\
\hline Lysine decarboxylase & - & - & - & - & - & - \\
\hline Ornithine décarboxylase & - & + & + & + & - & + \\
\hline Citrate utilisation & - & + & + & - & + & - \\
\hline Production of $\mathrm{H}_{2} \mathrm{~S}$ & - & - & - & - & - & - \\
\hline Urea & - & - & - & - & - & - \\
\hline Tryptophane deaminase & - & + & - & - & + & - \\
\hline Production of indole & - & + & + & + & + & + \\
\hline V.P & + & - & + & - & + & - \\
\hline Gelatinase & + & - & + & + & + & - \\
\hline \multicolumn{7}{|l|}{ Fermentation } \\
\hline Glucose & + & + & + & + & + & + \\
\hline Mannitol & + & + & - & + & + & - \\
\hline Inositol & + & - & - & - & - & + \\
\hline Sorbitol & + & - & - & - & - & - \\
\hline Rhamnose & + & - & - & - & - & - \\
\hline Sucrose & + & + & - & + & + & - \\
\hline Melobiose & - & - & - & - & - & - \\
\hline Amygdaline & + & - & + & + & - & - \\
\hline Arabinose & - & + & - & - & - & - \\
\hline Lactose & nd & - & + & + & nd & nd \\
\hline
\end{tabular}

bacterial resistance to clinically relevant antibiotics (Austin and Adams, 1996). Castro-Escarpulli et al. (2003) showed a $100 \%$ resistance to ampicillin of the different stumps of Aeromonas spp. isolated from frozen fishes intended for human consumption in Mexico. They found out that this result is in accordance with those obtained by other authors on clinical strains (Morita et al., 1994). Toranzo et al. (1987) showed a similar resistance on stumps of freestanding Vibrios of salmon coming from the Atlantic coasts of Spain; they associated this resistance to doses of antibiotics used in aquaculture. V. vulnificus has been reported as the most significant species in terms of public health (Lewine and Griffin, 1993; Hladly, 1997).

Angelo Depaola et al. (1995) found a resistance of $97.3 \%$ of $P$. shigelloides strains to ampicillin, during the survey on antibioresistance freestanding gram negative bacterium of cat-fishes. It is important to underline that $P$. shigelloides and $A$. hydrophilla are bacteria opportunists in human pathology. If they can survive in the human intestine or can colonize it, they have the potential to confer resistance to antibiotics to the normal microflora or pathogenic microbes (Angelo Depaola et al, 1995). Resistance to nitrofurantoin is not in accordance with the results of Castro-Escarpulli et al. (2003) who found a $0 \%$ percentage resistance for all strains of Aeromonas spp. studied. Similarly, Angelo Depaola et al. (1995) found a resistance of $0 \%$ in all stumps of $P$. shigelloides. Sensitivity of the studied strain to chloramphenicol is in accordance with the results of Angelo Depaola et al. (1995) who found in their work that $P$. shigelloides and $A$. hydrophilla had a sensitivity of $80 \%$. Similarly, the 
Table 4. Percentage resistance to antibiotics of the isolated Vibrionaceaes of fishes.

\begin{tabular}{|c|c|c|c|c|c|c|c|}
\hline \multirow[b]{2}{*}{ Antibiotic dose } & \multirow[b]{2}{*}{$\begin{array}{c}\text { Respons } \\
\text { e }\end{array}$} & \multicolumn{6}{|c|}{ Percentage (\%) } \\
\hline & & $\begin{array}{c}V . \\
\text { metschnikovi } \\
i \\
(\mathrm{n}=15)\end{array}$ & $\begin{array}{c}V . \\
\text { alginolyticu } \\
s \\
(n=11)\end{array}$ & $\begin{array}{c}V . \\
\text { vulnificu } \\
s \\
(n=13)\end{array}$ & $\begin{array}{c}\text { A. } \\
\text { hydrophila } \\
(\mathrm{n}=26)\end{array}$ & $\begin{array}{c}\text { A. sobria } \\
(n=13)\end{array}$ & $\begin{array}{c}P . \\
\text { shigelloides } \\
(\mathrm{n}=14)\end{array}$ \\
\hline \multirow{3}{*}{ Ampicilline $(10 \mu \mathrm{g})$} & $\mathrm{R}$ & 100 & 100 & 100 & 100 & 100 & 100 \\
\hline & 1 & 0 & 0 & 0 & 0 & 0 & 0 \\
\hline & $\mathrm{S}$ & 0 & 0 & 0 & 0 & 0 & 0 \\
\hline \multirow{3}{*}{ Chloramphenic $(30 \mu \mathrm{g})$} & $\mathrm{R}$ & 13 & 82 & 0 & 0 & 0 & 14 \\
\hline & I & 0 & 18 & 31 & 46 & 15 & 14 \\
\hline & S & 87 & 0 & 69 & 54 & 85 & 72 \\
\hline \multirow{3}{*}{ Flumequine $(30 \mu \mathrm{g})$} & $\mathrm{R}$ & 20 & 90 & 31 & 26 & 15 & 0 \\
\hline & 1 & 33 & 10 & 0 & 12 & 8 & 0 \\
\hline & $S$ & 47 & 0 & 69 & 62 & 77 & 100 \\
\hline \multirow{3}{*}{ Nalidixic Acid $(30 \mu \mathrm{g})$} & $\mathrm{R}$ & 20 & 90 & 31 & 4 & 8 & 7 \\
\hline & I & 13 & 10 & 61 & 1 & 0 & 57 \\
\hline & S & 67 & 0 & 8 & 95 & 92 & 36 \\
\hline \multirow{3}{*}{ Nitrofurantoin $(300 \mu \mathrm{g})$} & $\mathrm{R}$ & 60 & 90 & 39 & 100 & 77 & 21 \\
\hline & 1 & 40 & 10 & 61 & 0 & 23 & 0 \\
\hline & $S$ & 0 & 0 & 0 & 0 & 0 & 79 \\
\hline \multirow{3}{*}{ Oxolinic Acid $(10 \mu \mathrm{g})$} & $\mathrm{R}$ & 0 & 10 & 23 & 12 & 0 & 0 \\
\hline & I & 0 & 0 & 16 & 0 & 0 & 0 \\
\hline & $S$ & 100 & 90 & 61 & 88 & 100 & 100 \\
\hline \multirow{3}{*}{ Oxytetracycline $(30 \mu \mathrm{g})$} & $\mathrm{R}$ & 20 & 27 & 39 & 0 & 0 & 14 \\
\hline & I & 67 & 73 & 16 & 88 & 62 & 14 \\
\hline & S & 13 & 0 & 45 & 12 & 38 & 72 \\
\hline \multirow{3}{*}{ Streptomycine $(10 \mu \mathrm{g})$} & $\mathrm{R}$ & 0 & 10 & 23 & 12 & 15 & 7 \\
\hline & 1 & 0 & 0 & 31 & 0 & 0 & 64 \\
\hline & $S$ & 100 & 90 & 46 & 88 & 85 & 29 \\
\hline \multirow{3}{*}{ Sulfamid (200 $\mu \mathrm{g})$} & $\mathrm{R}$ & 40 & 0 & 23 & 88 & 62 & 21 \\
\hline & I & 13 & 90 & 0 & 12 & 23 & 50 \\
\hline & $\mathrm{S}$ & 47 & 10 & 77 & 0 & 15 & 39 \\
\hline \multirow{3}{*}{$\begin{array}{l}\text { Trimethoprim + } \\
\text { sulfamethoxazole }\end{array}$} & $\mathrm{R}$ & 67 & 82 & 61 & 46 & 31 & 29 \\
\hline & 1 & 20 & 18 & 39 & 26 & 46 & 57 \\
\hline & $\mathrm{S}$ & 13 & 0 & 0 & 27 & 23 & 14 \\
\hline
\end{tabular}

S, Susceptible; I, intermediate; R, resistant.

sensitivity of strains to nalidixic and oxolinic acids, as well as to streptomycin agrees with those gotten on the studied stumps in the hospital (Kämpfer et al., 1999). The present work highlights an important incidence of Vibrionaceae (Aeromonas spp., Vibrio spp., and Plesiomonas spp.), in tilapias from four lakes in north Cameroon. The high presence of antimicrobial resistance This work highlights an important incidence of Vibrionaceae (Aeromonas spp., Vibrio spp., and Detected in these strains should not be underestimated. In conclusion, the environmental incidence of resistance to chloramphenicol seems to be increasing for $V$. alginoliticus, as well as an intermediate number of oxytetracycline. The aquaculture environment may thereby constitute a reservoir for bacterial resistance due to increasing use of antibiotics in the medical treatment of diseases.

\section{ACKNOWLEDGEMENTS}

Our gratitude goes to the Academic Agency of the Francophonie (AUF) which financed this work through the project PCSI 6312PS504/BAC 2005-0071. We thank all the personnel of the laboratory of Molecular Biology of the UMR briskly 95 Qualisud of the CIRAD of Montpellier (France) who had treated tactfully the effort for the realization of these works. 


\section{REFERENCES}

Angelo De Paola, James T, Peeler, Gary E, Rodrick (1995). Effect of Oxytetracycline-Medicated feed on Antibiotic resistance f Gramnegative bacteria in catfish ponds. Appl. Environ. Microbiol. pp. 2335-2340.

Annapurna E, Sanyal SC (1977). Enterotoxicity of Aeromonas hydrophila. J. Med. 10 (3): 317- 323.

Aoki T (1992). Present and future problems concerning the development of resistance in aquaculture. In: Michel C, Alderman D (eds) Chemotherapy in aquaculture: from theory to reality. Office International des Epizoties, Paris, France, pp. 254-262.

Apun K, Yus of AM, Jugang K (1999). Distribution of bacteria in tropical freshwater fish and ponds. Int. J. Environ. Health research 9: 285292.

Austin B, Austin DA (1993). Bacterial fish pathogens: Disease in farmed and wild fish (Ellis Horwood series in Aquaculture \& Fisheries Support), Taylor \& Francis, $2^{\text {nd }}$ ed. Chichester, United Kingdom.

Austin B, Adams C (1996). Fish pathogens. In: Austin B, Altwegg M, Gosling PJ, Joseph S (Eds.), The Genus Aeromonas. Wiley, Chichester, pp. 198-243.

Castro-Escarpulli G,Figueras MJ, Aguilera-Arreola G, Soler L, Fernández-Rendón E, Aparicio GO, Guarro J, Chacón MR (2003). characterisation of Aeromonas spp. Isolated from frozen fish intended for human consumption in Mexico. Int. J. food Microb. 84: 41-49.

Chang B, Bolton SM (1987). Plasmids and resistance to antimicrobial agents in Aeromonas sobria and Aeromonas hydrophila clinical isolates. Antimicrob. Agents and Chemother. 31: 1281-2.

De Sousa JA, et Silva-Souza A.T (2001). Bacterial community associated with fis hand water from Congonhas River, Sertneja, parana, Brazil. Brazilian Archives of boil. Technol. 44: 373-381.FAO (2004). Appui à la révision du cadre juridique des pêches et de l'aquaculture au Cameroun. FAO/TCP/CMR/2907(A).

Guardabassi L, Dalsgaard A, Raffatellu M, Olsen JE (2000). Increase in the prevalence of oxolinic acid resistant Acinetobacter spp. observed in a stream receiving the effluent from a freshwater trout farm following treatment with oxolinic acid-medicated feed. Aquaculture, 188: 205-218.

Hladly WG (1997). Vibrio infections associated with raw oyster consumption in Florida, 1981-1984. J. of Food Protec. 60: 353-357.

Kado Cl, Liu FT (1981). Rapid procedure for detection and isolation of large and small plasmid. J.Bacteriol. 145:1365-1373.

Kämpfer P, Christmann C, Swings J, Huys G (1999). in vitro susceptibitlies of Aeromonas genomic species to 69 antimicrobial agents. Syst. Appl. Microbial. 22: 662-669.

Lewine WC, Grffin PM (1993). Gulf Coast Vibrio Working Group, Vibrio infection on the Gulf Coast: Results of first year of regional surveillance. J. infec. Diseases, 167: 479-483.

Morita KL, Watanabe N, Kurata S, Kanamori M (1994). $\beta$-lactam resistance of motile Aeromonas isolated fromclinical and environemental sources. Antimicrob. Agents chemother, 38: 353-355.

Ofimer (2002). Tilapia et perche du Nil. Des alternatives sur le marché du

poissonblanc.http:/www.ofimer.fr/PDF/obseco/11_noteshemp_e_dou ce.PDF.

Popoff M, Veron M (1976). A taxonomic study of the Aeromonas hydrophila-Aeromonas punctata group. J. Gen. Microbiol. 94:11-22.

Rasmussen BA, Bush K (1997). Carbapenem hydrolyzing $\beta$ lactamases. Antimicrob agent chemother 41:223-232.
Ratanaporn Leesing (2005). Identification et validation de marqueurs spécifiques pour la traçabilité de poisons d'aquaculture lors de leur import/export. Thèse en Science des Aliments. Université de Montpellier II, 183p.

Schmidt AS, Bruun MS, Dalsgaard I, Larsen JL (2001).Charac-terization of class 1 integrons associated with R-plasmids in clinical Aeromonas salmonicida isolates from various geographical areas.J.Antimicrob.Chemother. 47:735-743.

Spanggaard B, Jorgensen F, Gram L, Huss HH (1993). Antibiotic resistance in bacteria isolated from three freshwater fish farms and an unpolluted stream in Denmark. Aquaculture, 115: 195-207.

Stead D (1992). Grouping of plant-pathogenic and some other Pseudomonas spp. by using cellular fatty acid profiles. Int. J. Syst. Bacteriol, 42: 281-295.

Sugita $H$, Shibuya $\mathrm{KH}$, Deguchi $\mathrm{Y}$ (1996). Antibacterial abilities of intestinal bacteria in freshwater cultured fish. Aquaculture, 145: 195203.

Thompson FL, Hoste B, Vandemeulebreocke K, Swings J (2001). Genomic diversity amongst Vibrio isloted from different sources detremined by fluorescent amplified fragment length polymorphism. Syt Appl Micobiol. 24:520-538.

Toranzo AE, Santos Y, Lemos ML, Ledo A, Bolinches J (1987). homology of Vibrio anguillarum strains causing epizootics in turbot, salmon and trout reared on the Atlantic coast of Spain. Aquaculture. 67: 841-52. 